\title{
Technology-Based Industrialization of Claims Management in Motor Insurance
}

\author{
Oliver Baecker, Albrecht Bereuter \\ Institute of Technology Management, \\ University of St. Gallen \\ \{oliver.baecker|albrecht.bereuter\}@unisg.ch
}

\section{Introduction}

Over the past years, German motor insurers have been facing growing competition from in- and outside the industry (e.g., car manufacturers, automobile clubs) (Kaeslin and El Hage 2008). Together with a growing pricing pressure on insurance premiums, their combined ratio increased from $94.5 \%$ in 2004 to $101.6 \%$ in 2008 (GDV 2009). At the same time, motor insurance is the class of business with by far the largest volumes within property and casualty insurance with a total of 20.4 billion Euros in premiums (German market in 2008). This indicates that cost savings and efficient process improvements in claims management business processes have a great impact on the key performance indicators of insurers. However, over the last years, earned premiums were decreasing while motor insurers were unable to decrease costs to the same degree. The main reasons why cost savings are hard to achieve include the late involvement of insurers after car accidents, the limited integration of business partners such as repair shops, and improper information about the case circumstances (Kaeslin and El Hage 2008). According to several studies (Accenture 2002; Bieber and Hoberg 2007; Mueller and Kuefner 2003), earlier and more detailed information about motor insurance claims could enable pro-active claims management and shorten the average claim life-cycle from set-up to close as well as decrease the average costs per case. In addition, an early notification simplifies the integration of business partners for settling a claim and enables the insurance company to benefit from volume discounts, for example, by routing their customers to authorized repair shops. However, according to a study by Kaeslin and El Hage (2008), at most $7.5 \%$ of all motor insurance claims are managed pro-actively. The untapped potential was investigated by Accenture (2002) during an analysis of 12,000 settled claims and led to the estimate that cost savings of up to $15 \%$ are possible, while further studies indicate similar results (Bieber and Hoberg 2007; Mueller and Kuefner 2003). This 
cost saving potential equals a double-digit million Euros saving per year for a midsize insurer.

While insurance companies are under pressure to decrease costs, customers lack adequate assistance when it comes to an insurance claim, the so-called "moment of truth" where an insurer has to put his value proposition into practice. In such unpleasant and emotionally stressful situations, customers require both immediate services and support with the submission of a loss report to their insurance carrier. Against this background, the usage of mobile phones can address the outlined problems of insurance carriers and the needs of their customers. From a customer perspective, mobile phones are ubiquitously available, e.g., the average mobile phone penetration rate in the European Union was 119\% in 2008 (European Commission 2009a). At the same time, the mobile phone has emerged as the most dominant mediation device in safety-critical situations. Qualitative interview data as well as quantitative analysis show that people's sense about mobile phones is to never be alone in emergencies (Ling 2004). Accordingly, mobile technology can play an important role in the aftermath of car accidents to report an insurance claim and to benefit from value-added services. While this approach provides customers with adequate assistance, it can also lead to more efficient claims management business processes for insurers as we will outline in this paper.

The contribution of this paper comprises both technical aspects and business aspects. In section 3, we present an analysis of today's claims management process in motor insurance and describe four technology-based process improvements. In order to realize the process improvements, a service-oriented architecture is presented and the implementation of a demonstrator illustrates our solution in section 4. We propose several business value metrics to measure the effects linked with each process improvement in section 5 and conclude with our main findings and an outlook on future work in section 6 . Our work follows the research method of design science (Hevner et al. 2004). Starting from a business need, we developed a demonstrator ("artifact") and evaluated it in order to generate a useful contribution to the application environment as well as to rigorously contribute to the knowledge base. The business need was identified based on desk research, expert interviews, and seven focus groups that were joined by representatives of seven different insurance companies, differing students, and the authors of this paper.

\section{Related Work}

This section presents related work from academia and industry. We first highlight work that documents the need for an industrialization of claims management and then discuss technological developments, which are relevant to our approach.

In 2008, Kaeslin and El Hage conducted a case study in order to identify potential cost reductions for claims management in motor insurance. The authors highlight the long average time needed to settle a claim due to the lack of process 
automation. Furthermore, they identify the need for an early contact between the insured and the respective insurance company in order to pro-actively guide customers during the claim settlement. Kaeslin and El Hage argue that a lack of adequate IT solutions is one of the challenges that insurance companies need to address in order to improve control over the claims management processes.

Lee et al. (2007) present an empirical study to examine possible strategies and applications for mobile commerce in the insurance industry. They conducted a survey amongst insurance agents in order to explore, which mobile solutions are applicable and identify possible benefits for the agents' tasks. The authors conclude that personal digital assistant (PDA) technology is appropriate for the insurance industry and highlight the potential for improvements of customer care and claims management (post-contract customer services).

Two domains related to mobile technology where insurance applications are rapidly emerging are telematics and Car-2-X (Festag et al. 2008). Motor vehicles get connected to insurance enterprise systems, which enables usage-based pricing models (Litman 2008), allows for emergency calls (European Commission 2009b), and facilitates recording of crash data (Octo Telematics 2009). Amongst others, the efforts are driven by the eSafety initiative of the European Commission (2009b). This initiative incorporates the eCall technology, which enables automatic accident detection and an emergency call including a combination of voice communication and data transfer.

While the outlined applications are currently deployed in motor vehicles, similar applications will become available for mobile phones as their computational power increases, additional sensor technology becomes available, and mobile phones get integrated with enterprise systems (Want 2009). As an example, the USbased insurance companies Nationwide ${ }^{1}$ and Farmers ${ }^{2}$ recently published two applications on the iTunes App Store, which support users with a loss report from the iPhone. Our demonstrator differs from both applications as it is integrated with a commercial claims management enterprise system and provides locationbased services instead of simply capturing and transmitting data via e-mail.

Leading providers of enterprise applications already consider the integration of mobile devices into the claims management process. The common goal is the automation of certain process steps in order to achieve a more consumer-oriented service. As a prominent example, Microsoft installed PDA technology and provided for its integration at a large property and casualty insurance (Microsoft 2007). The insurance company claims that the project reduced the workload on underwriters by $20 \%$. IBM aims for similar goals with their business solution for insurance claims. Their goal is to reduce the processing time for claims requiring "low- to notouch management", which they estimate to be up to $60 \%$ of all claims (IBM

\footnotetext{
${ }^{1}$ http://www.nationwide.com/mobile/iPhone-support.jsp

2 http://www.farmers.com/iclaim.html
} 
2009). The solution is based on the automation of steps in the life-cycle of a claim, but also enables the customer to file a claim at any time through a web portal.

\section{Industrialization of Claims Management}

As outlined in section 1, mobile technology can foster the industrialization of claims management business processes. However, as a first step, it is necessary to understand, in which areas of the overall business process technology-based improvements can be expected. We therefore start with an overview of a claims management process as it is implemented by most insurers today. As a next step, we discuss how this process can be improved and which process steps need to be adapted. We use the Business Process Modeling Notation (BPMN) as a graphical representation of the claims management process, due to its widespread adoption in process modeling. For the sake of simplicity, the BPMN diagram in Figure 1 only shows the customer process and the process of an insurance company, while the interaction with third parties such as repair shops, appraisers, or lawyers is an implicit part of the two aforementioned processes. The customer process starts with the occurrence of a car accident. Usually after some delay, an insurance company learns about the accident via traditional channels such as letter, phone call, or online portal. As a next step, case circumstances are submitted as part of the loss report and the insurance company creates a first notice of loss. After the claim evaluation, the insurance company requests further information, for example, to assess the damage or to clarify the question of guilt. Finally, the claim is settled and, if applicable, a payment is issued.

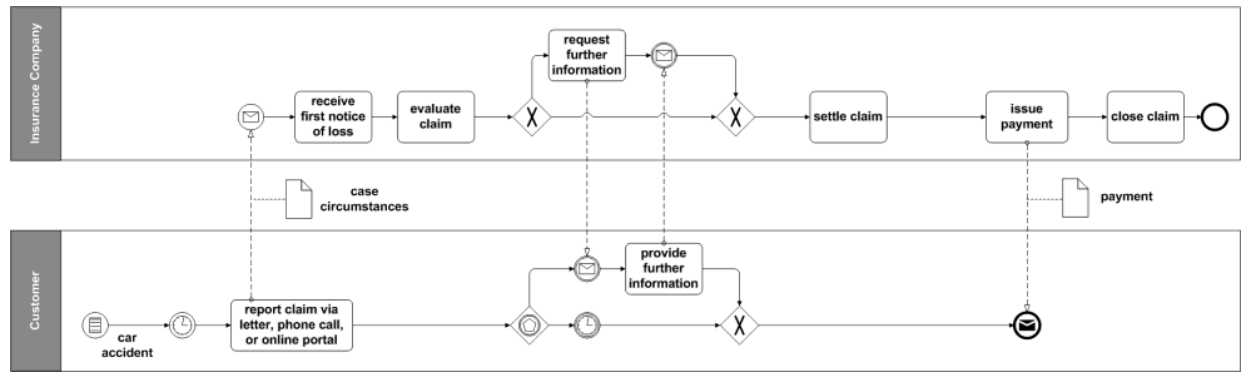

Figure 1: Claims Management Business Process

Based on the presented claims management process, four major areas of improvement are identified and highlighted in gray in the BPMN diagram in Figure 2:

a) Mobile loss report: Customers can use a mobile phone application to place an emergency call after a car accident. In case of a minor incident, an insurance call center agent guides customers through the process of collecting case circumstances (e.g., pictures of the accident scene) and submitting the informa- 
tion to a claims management enterprise system. The immediate and automated involvement of insurance companies enables an improved process management and the early integration of business partners. At the same time, the direct data transmission avoids media breaks (characteristic in case of loss reports via phone calls or letters), which could lead to wrong or incomplete claim data (Fleisch and Mattern 2005).

b) Partner management: Based on the mobile loss report, insurance companies can simplify the claim handling process and integrate their business partners at an earlier point in time. The insurers directly support customers with context information like the location of the next repair shop, and a tow truck can be sent to the customer's location. The direct involvement of authorized repair shops and further selected business partners like appraisers reduces loss expenses and shortens the processing time of a claim. While leading to a faster claim settlement and reduced costs, the efficient management of the claim process also leads to an increased customer satisfaction.

c) Status notification: Customers can decide to receive status notifications, based on changes in the claims management enterprise system. Notifications are triggered by events within the enterprise system and keep customers informed about the status of their claims. For example, in Figure 2, a status update is sent after the insurance company settled the claim. The immediate feedback reassures customers that the insurance company takes care of their worries and leads to an improved customer satisfaction.

d) Customer feedback: For insurance carriers, it is important to receive feedback from customers after the settlement of an insurance claims. This concerns a customer's overall satisfaction, but also his rating of services provided by business partners. Using mobile phones, customers can easily provide their feedback after a claim settlement, while insurers can store and analyze the respective data in their customer relationship management (CRM) systems.

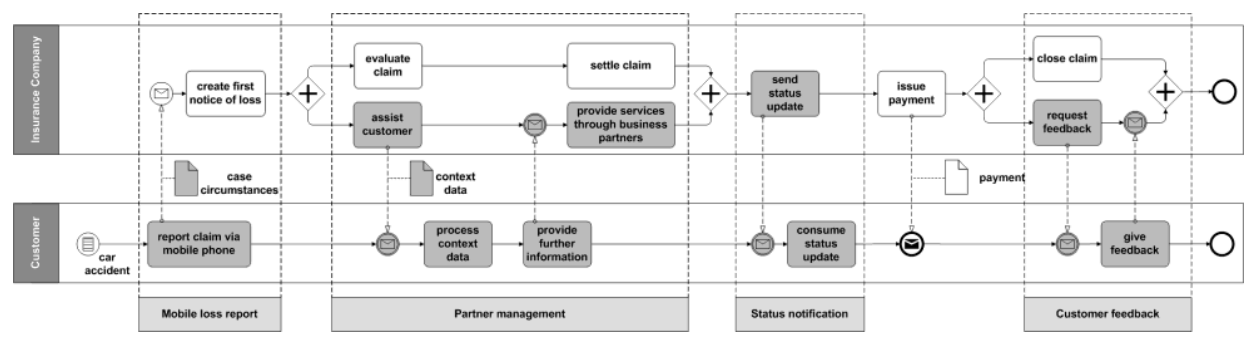

Figure 2: Novel Claims Management Business Process 


\section{Integration Architecture and Demonstrator}

In order to increase the efficiency of today's claims management processes and to reach the discussed process improvements, the integration between mobile phones and claims management enterprise systems is necessary. Therefore, in the following section 4.1, we describe an architecture, which enables the described process improvements. In section 4.2 , we present a demonstrator based on the architecture, which illustrates our solution.

\subsection{Integration Architecture}

The most important technical challenge of our approach is to bridge the gap between the business application layer (e.g., claims management enterprise systems) and the device layer (e.g., mobile phones). Against this background, we highlight the need for an integration architecture, which acts as a connecting bridge. For this, we propose the exploitation of the Service-Oriented Architecture (SOA) paradigm. More specifically, web services offer the required functionality to abstract from technological differences and ensure a common communication protocol. Building an integration architecture based on web service technology eliminates the complexity of connecting different technologies, using concepts such as a mobile middleware (Varshney and Vetter 2001), and provides for a seamless integration of all involved layers. Furthermore, the concept of web services is recently also pushed to the device layer. Examples of these efforts are the Devices Profile for Web Services (DPWS) standard ${ }^{3}$, and further efforts for providing web services on mobile phones (Ellis and Young 2003). Building upon the concept of web service technology, we propose a service-oriented architecture, which facilitates the direct involvement of mobile phones into claims management business processes. The FMC (Fundamental Modeling Concepts) block diagram in Figure 3 depicts the infrastructure underlying the claims management scenario, including the integration architecture, which enables the process improvements described in the previous section. The integration architecture consists of several loosely-coupled components, which facilitate the integration of smart devices with business applications. The Event Handler (Hohpe and Woolf 2007) component is at the core of our architecture, as it enables the communication across different layers via well-defined interfaces. In order to provide for compatibility, we decided to use the OASIS Web Service Notification (WSN) standard 4 . The standard incorporates the publication (push mechanism) of certain events to subscribers through a generic web service operation (reduces the generated traffic) or via a pull mechanism (valuable when using devices with limited capabilities). The Invocation Handler component manages the invocation of web services offered by mobile

\footnotetext{
3 http://www.oasis-open.org/committees/ws-dd/

${ }^{4}$ www.oasis-open.org/committees/wsn/
} 
phones. Finally, the Business Connector component encapsulates the application logic needed for transforming device layer events to actions in business applications and vice versa.

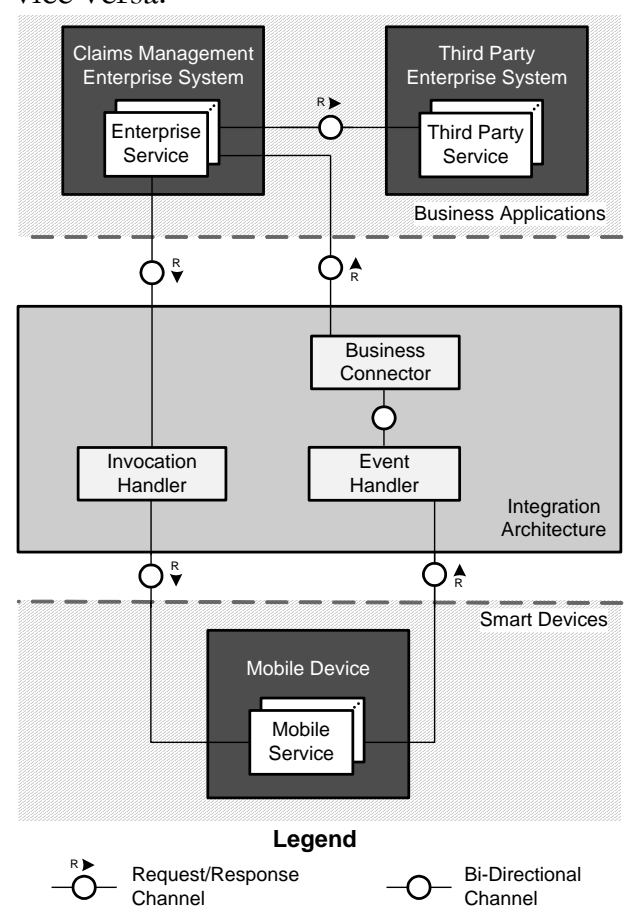

\section{Figure 3: Integration Architecture}

\subsection{Demonstrator "Mobile Claims Assistance"}

In order to show the feasibility of our solution and to verify the interest in and acceptance of our approach, we implemented a demonstrator. This section presents the setup of our demonstrator implementation as well as the rationale behind our design decisions. The demonstrator shows the integration of a mobile phone into a business process executed in a claims management enterprise system. As such, the demonstrator incorporates three major components:

a) Mobile phone application: We built client applications for the Android platform, Blackberry OS, and iPhone OS. For testing purposes, we deployed our applications on HTC's G1, the HTC Magic, the HTC Hero (all Android-based), an iPhone 3G, and the Blackberry Storm 9500.

b) Service-oriented integration architecture: The integration architecture is realized as a set of Java Enterprise Edition (EE) components, which fulfill the requirements outlined in the previous section. The proliferation of Java EE application serv- 
ers in enterprise environments and the provided support for web service standards were the main drivers for this choice.

c) Claims management enterprise system: The commercial claims management solution "SAP Claims Management 6.0 EHP4"5 is used as the third component, as it provides access to core enterprise functionality via web services, therewith fulfilling our requirement for a service-oriented architecture.

The demonstrator is based on the application scenario outlined in section 3. After a car accident, a customer uses the mobile phone to submit a loss report. For this purpose, the client application on the mobile phone invokes a web service operation provided by the Event Handler component, sending information such as GPS location data and the car registration. In addition, the customer uses the camera of the mobile phone to take pictures of the accident, which are attached to the loss report. The demonstrator also shows how the exchange of insurance data between involved parties after an accident could look like. A QR Code (a two-dimensional barcode) is read from the insurance card of the other party after the accident. This code contains insurance-specific data, like the insurance company and the policy number of the insurance holder. The scanning of the QR Code adds valuable information to the existing case circumstances that are sent to the SAP Claims Management solution. Figure 4 shows screenshots of the client application running on the three different mobile phone platforms.

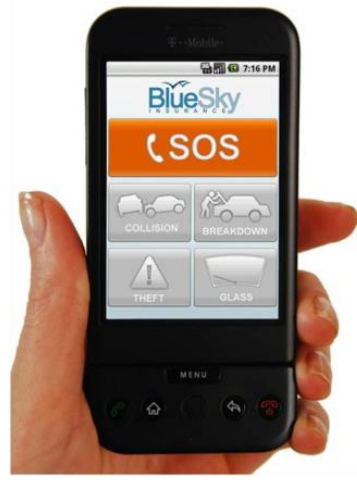

Android

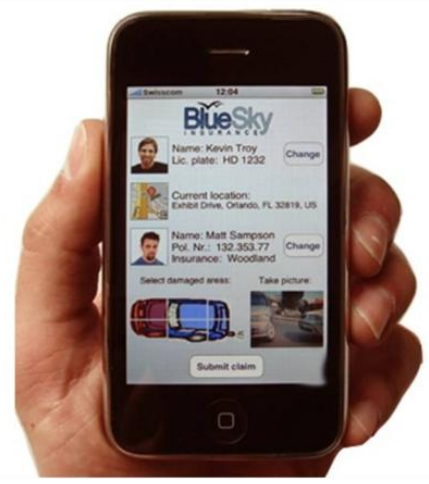

iPhone OS

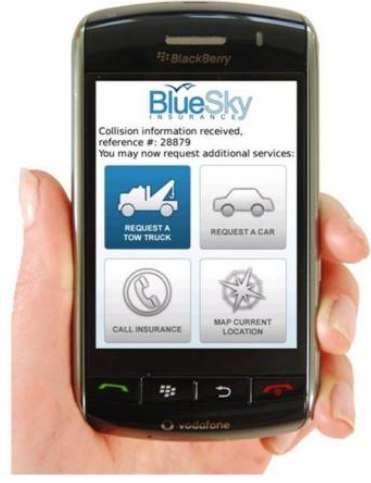

Blackberry OS

\section{Figure 4: Demonstrator "Mobile Claims Assistance"}

In order to process the loss report, the Event Handler implements the OASIS WSN standard introduced earlier. Using a "publish / subscribe" mechanism, the Business Connector component is notified of the request and triggers the corresponding actions in the SAP Claims Management solution through a web service call. After the business application has successfully created the claim and respective further actions are triggered (e.g., the notification of third party service providers), the infor-

${ }^{5}$ http://www.sap.com/industries/insurance/claimsmanagement.epx 
mation is propagated back to the customer's mobile phone via the Invocation Handler. This includes information about the current status of the claim as well as assistance for possible next steps. Offered location-based services include the routing to the closest authorized repair shop, the ordering of a towing service, or the request for a rental car. The mobile phone application also provides details about the customer's insurance policy, like his eligibility for a rental car as well as the ID of the recently created claim.

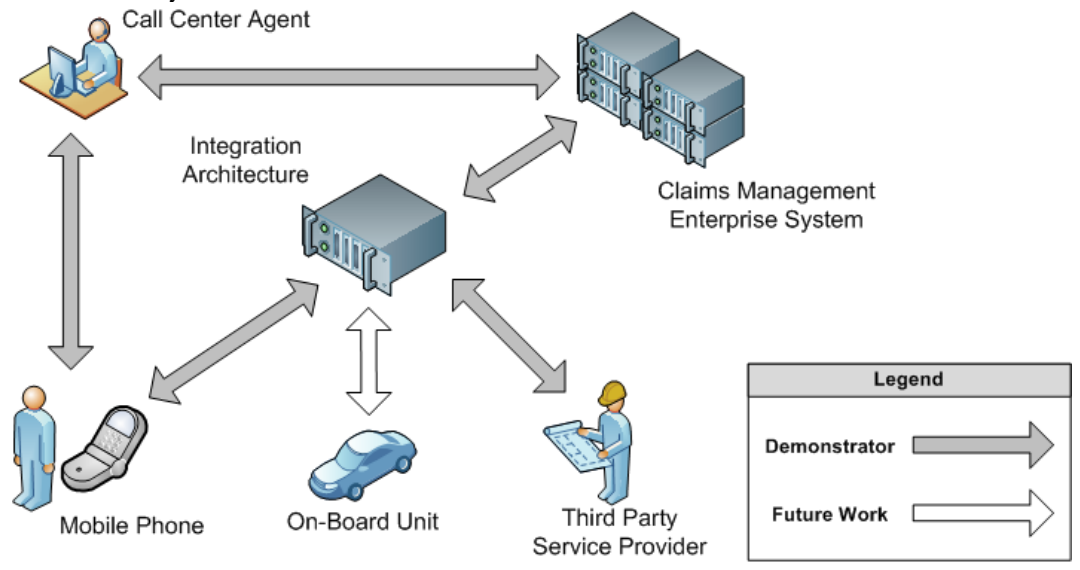

Figure 5: Application Scenario

Figure 5 summarizes the described scenario and highlights the process improvements presented in section 3. A first area of improvement is the initiation of the claims process via a mobile phone, which addresses the "mobile loss report" functionality. Furthermore, the mobile phone application can consume locationbased services (see above) offered by business partners of the insurance carrier, therewith illustrating the possible process improvements summarized as "partner management". In addition, the insured is notified that the claim process started after the first notice of loss was created, thus fulfilling basic requirements for the improvements outlined as "status notification". Finally, insurance companies can request "customer feedback" and business partner ratings from within their claims management system. As future work, the integration of a pre-configured on-board unit will enable the loss report from a car, which includes detailed accident data coming from in-car sensors. This report can be submitted automatically (e.g., when the airbag is deployed) or by pressing a dedicated button.

\section{Business Value Metrics}

This section complements the previous technical work by an analysis of the types of processes and effects that result from the four process improvements outlined 
in section 3. In addition, this section gives an overview of business value metrics that can be applied to measure the business value of the proposed process improvements. It is important to note that the identified improvements of the claims management value chain occur at a process level. Thus, process-oriented metrics rather than firm-level output measures of value need to be considered to assess the business value of the demonstrator. In order to develop an understanding of adequate value metrics, the IT impact framework proposed by Mooney et al. (1996) is applied. The framework is based on Davenport's (1993) classification of operational (i.e., a firm's value chain) and management (i.e., information processing, control, coordination, and communication) processes, and distinguishes between automational, informational, and transformational effects. Automational effects refer to IT-based cost reductions and productivity improvements, informational effects result from the impact of IT on information capturing and processing, and transformational effects refer to the ability of IT to support process improvements. Table 1 outlines potential business value metrics of our solution structured according to the underlying process and effect types. The table also indicates the relation to the process improvements introduced in section 3.

Table 1: Business Value Metrics

\begin{tabular}{|c|c|c|c|}
\hline Process Type & Effect Type & $\begin{array}{l}\text { Business Value } \\
\text { Metrics }\end{array}$ & $\begin{array}{l}\text { Process } \\
\text { Improvements }\end{array}$ \\
\hline \multirow{3}{*}{ Operational } & Automational & $\begin{array}{ll}\text { - } & \text { Processing time } \\
\text { - } & \text { Loss expenses } \\
\text { - } & \text { Operating costs } \\
\text { - } & \text { Data acquisition costs }\end{array}$ & $\begin{array}{l}\text { - } \quad \text { Mobile loss report } \\
\text { - } \quad \text { Partner management }\end{array}$ \\
\hline & Informational & $\begin{array}{ll}\text { - } & \text { Media breaks } \\
\text { - } & \text { Data quality } \\
\text { - } & \text { Data completeness } \\
\end{array}$ & $\begin{array}{ll}\text { - } & \text { Mobile loss report } \\
\text { - } & \text { Status notification } \\
\text { - } & \text { Customer feedback } \\
\end{array}$ \\
\hline & Transformational & $\begin{array}{ll}\text { - } & \text { Service innovation } \\
\text { - } & \text { Quality of partnerships } \\
\text { - } & \text { Customer satisfaction } \\
\end{array}$ & $\begin{array}{ll}\text { - } & \text { Mobile loss report } \\
\text { - } & \text { Partner management } \\
\text { - } & \text { Customer feedback } \\
\end{array}$ \\
\hline \multirow{3}{*}{ Management } & Automational & $\begin{array}{ll}\text { - } & \text { Standardization } \\
\text { - } & \text { Control } \\
\end{array}$ & - $\quad$ Partner management \\
\hline & Informational & $\begin{array}{ll}\text { - } & \text { Decision quality } \\
\text { - } & \text { Effectiveness of commu- } \\
\text { nication }\end{array}$ & $\begin{array}{ll}\text { - } & \text { Mobile loss report } \\
\text { - } & \text { Customer feedback }\end{array}$ \\
\hline & Transformational & - Competitive advantages & $\begin{array}{ll}\text { - } & \text { Partner management } \\
\text { - } & \text { Customer feedback } \\
\end{array}$ \\
\hline
\end{tabular}




\section{Conclusions and Future Work}

In this paper, we presented an analysis of today's claims management processes in motor insurance, and identified several areas for technology-based process improvements. In order to establish the technical foundation for their realization, we designed and implemented a service-oriented architecture and used it to develop a demonstrator, which illustrates the identified process improvements. The technical work was complemented by an analysis of the underlying process and effect types as well as by an overview of business value metrics that can be used to measure the impact of the proposed process improvements. Our paper demonstrated the benefits of a mobile claims assistance application for customers involved in a car accident as well as for insurance companies. In addition, we demonstrated that mobile phones are technically capable of reporting claims into commercial claims management enterprise systems. Based on this work, it will be possible to transfer the concepts to related classes within property and casualty insurance, such as household contents insurance or building insurance.

As future work, we will conduct a user study with insurance customers to evaluate the solution. As part of the study, participants will use the "Mobile Claims Assistance" solution to re-enact a recent personal loss report. The goal is to investigate whether customers are really willing to use the application in case of an insurance claim and to compare the mobile application with the experienced loss report via phone or internet. In addition, future research will investigate which convenience services (e.g., the navigation to the cheapest close-by gas station) could complement the functional range of the proposed claims assistance application. Up to now, we focused on a technical solution and its business value. Thus, future research needs to address data security and privacy with a special focus on the data exchange between mobile phones and insurance enterprise systems. Finally, we plan to integrate our application into motor vehicles. This means we will be able to enrich the case circumstances with in-vehicle sensor data.

\section{References}

Accenture (2002) Unlocking the Value in Claims, Accenture - Insurance Solution Group.

Bieber T, Hoberg S (2007) Aktives K-Schadenmanagement gemessen und bewertet. Versicherungswirtschaft 12:992-995.

Davenport T (1993) Process Innovation: Reengineering Work through Information Technology. Harvard Business School Press, Boston.

Ellis J, Young M (2003) J2ME Web Services 1.0, Final Draft, Sun Microsystems Inc, Santa Clara. http://jcp.org/en/jsr/detail?id=172. Retrieved 2009-09-29. 
European Commission (2009a) Progress Report on the Single European Electronic Communications Market 2008. http:/ / eurlex.europa.eu/LexUriServ/LexUriServ.do?uri=COM:2009:0140:FIN:EN:PDF. Retrieved 2009-10-04.

European Commission (2009b) eCall Toolbox. http://www.esafetysupport.org/en/ecall_toolbox. Retrieved 2009-09-29.

Festag A, Baldessari R, Zhang W, Le L, Sarma A, Fukukawa M (2008) CAR-2-X Communication for Safety and Infotainment in Europe. NEC Technical Journal 3(1).

Fleisch E and Mattern M (2005) Das Internet der Dinge: Ubiquitous Computing und RFID in der Praxis: Visionen, Technologien, Anwendungen, Handlungsanleitungen. Springer, Berlin.

GDV: Gesamtverband der deutschen Versicherungswirtschaft e.V. (2009) Statistisches Taschenbuch der Versicherungswirtschaft 2009.

Hevner A, March S, Park J, Ram S (2004) Design Science in Information Systems Research. MIS Quarterly 28(1):75-105.

Hohpe G, Woolf B (2007) Enterprise Integration Patterns, Addison-Wesley Professional.

IBM (2009) Fast path claims from IBM. http://www-03.ibm.com/industries/fin ancialservices/doc/content/solution/1231013103.html. Retrieved 2009-09-29.

Kaeslin B, El Hage B (2008) Kosteneinsparung durch aktives KfzReparaturmanagement. Versicherungsbetriebe 1:8-10.

Lee C, Cheng H K, Cheng H (2007) An empirical study of mobile commerce in insurance industry: Task-technology fit and individual differences. Decision Support Systems 43(1):95-110.

Ling R (2004) The mobile connection: the cell phone's impact on society, Morgan Kaufmann, San Francisco, USA.

Litman T (2008) Distance-Based Vehicle Insurance - Feasibility, Costs and Benefits. Comprehensive Technical Report, Victoria Transport Policy Institute.

Microsoft (2007) Southern Farm Bureau Casualty Insurance Company. http://www.microsoft.com/casestudies/Case_Study_Detail.aspx?CaseStudyI $\mathrm{D}=4000000960$. Retrieved 2009-09-29.

Mooney J G, Gurbaxani V, Kraemer K L (1996) A Process Oriented Framework for Assessing the Business Value of Information Technology. ACM SIGMIS Database 27(2):68-81. 
Mueller K-W, Kuefner R (2003) Schadenmanagement in der Versicherungswirtschaft. BearingPoint GmbH, Frankfurt.

Octo Telematics (2009) Insurance Telematics. http://www.octotelematics.com/ solutions/insurance-telematics/. Retrieved 2009-08-10.

Varshney U, Vetter R (2001) A Framework for the Emerging Mobile Commerce Applications. In: Proceedings of the 34th Annual Hawaii International Conference on System Sciences.

Want R (2009) When Cell Phones Become Computers. IEEE Pervasive Computing 8(2):2-5. 